\title{
AMAZđ̛́NAS
}

DOI: https://doi.org/10.34069/RA/2021.8.01

Volumen 4, Número 8/julio-diciembre 2021

Di Nicolo, C.A. (2021). Valoración histórica de los recursos naturales. El caso de Villa Pehuenia-Moquehue, provincia de Neuquén, Argentina. Revista Científica Del Amazonas, 4(8), 5-18. https://doi.org/10.34069/RA/2021.8.01

\section{Valoración histórica de los recursos naturales. El caso de Villa Pehuenia-Moquehue, provincia de Neuquén, Argentina}

\section{Historical valuation of natural resources. The case of Villa Pehuenia-Moquehue, Neuquén province, Argentina}

Recibido: 15 de enero de $2021 \quad$ Aceptado: 25 de febrero de 2021

Autores:

Carolina Andrea Di Nicolo ${ }^{1}$

\section{Resumen}

Villa Pehuenia-Moquehue es una localidad del centro oeste de la provincia de Neuquén, Argentina. Si bien en la actualidad cuenta con un claro perfil turístico, sus orígenes están relacionados con el desarrollo de otras actividades productivas como son la maderera y la ganadería extensiva. Ello supuso una diferente valoración social sobre los recursos naturales presentes, así como una determinada organización del territorio.

El objetivo central es mostrar esas diferencias a lo largo de los años hasta llegar a la actualidad donde el turismo es la actividad por excelencia en la villa.

Para ello se utilizaron fuentes primarias y secundarias. Para las primeras se realizó un importante trabajo de campo en el marco de la elaboración de la tesis doctoral de la autora en el cual se efectuaron entrevistas a personas clave del lugar y se captó valiosa información y fotografías como observador no participante. También se acudió a documentos legales, censos nacionales de población y vivienda, y se utilizaron fuentes bibliográficas que han realizado importantes estudios en el área.

Como resultado, el trabajo permite identificar tres momentos en la historia reciente de la villa con el desarrollo de tres actividades económicas diferentes y con especificidades en cuanto a la relación sociedad-naturaleza y a los rasgos que cada una le ha impreso a dicho territorio.

Palabras clave: Actividades económicas - recursos naturales-relación sociedad/naturaleza territorio- Villa Pehuenia-Moquehue.

\begin{abstract}
Villa Pehuenia-Moquehue is a town in the central west of the province of Neuquén, Argentina. Although it currently has a clear tourist profile, its origins are related to the development of other productive activities such as logging and extensive livestock farming. This meant a different social assessment of the natural resources present as well as a specific organization of the territory. The main objective is to show these differences over the years until reaching the present day where tourism is the activity par excellence in the town.

For this, primary and secondary sources were used. For the former, an important field work was carried out within the framework of the author's doctoral thesis, in which interviews were carried

\footnotetext{
${ }^{1}$ Doctora en geografía (UNLP), Buenos Aires, Argentina. Licenciada en Geografía y Técnica en Empresas de Servicios Turísticos (UNComa). Neuquén, Argentina. Docente de la Universidad Nacional del Comahue, Neuquén. Argentina. Becaria Posdoctoral
} IPEHCS CONICET, https://orcid.org/0000-0001-6908-4562
\end{abstract}




\section{AMAZONANAS}

out with key local people and valuable information and photographs were captured as a nonparticipating observer. Legal documents, national population and housing censuses were also used, and bibliographic sources that have carried out important studies in the study area were used.

As a result, this work allows us to identify three moments in the recent history of the town with the development of three different economic activities and with specificities in terms of the society-nature relationship and the features that each one has imprinted on said territory.

Keywords: Economic activities - natural resources-society-nature relationship - territory- Villa Pehuenia-Moquehue.

\section{Introducción}

Villa Pehuenia es un centro turístico cordillerano de la provincia del Neuquén. Se encuentra a la vera del lago Aluminé en el Departamento del mismo nombre, a $300 \mathrm{Km}$ de la capital provincial y a $1.461 \mathrm{~km}$ de Buenos Aires (CABA). Es la puerta de ingreso al corredor de los lagos patagónicos, y se halla a solo $15 \mathrm{Km}$ del paso Internacional Icalma que comunica la villa con Chile.

Es un destino turístico en crecimiento y su principal atractivo se sustenta en la gran belleza paisajística compuesta por lagos, montañas, bosques y el centro de ski, entre otros. Allí convive la cultura y la historia de la comunidad Mapuche Puel la cual gestiona el parque de nieve, y la Placido Puel, junto a la posibilidad del contacto con la naturaleza en un entorno de gran tranquilidad.

En la historia reciente de la villa es posible identificar distintos momentos en los cuales la relación sociedad-naturaleza ha cambiado. Se acude al concepto de recursos naturales para identificar la valorización social hecha sobre éstos así como el desarrollo de distintas actividades económicas a las que han dado origen.

De esta manera, el objetivo es analizar cómo ha sido la valoración histórica de los diferentes recursos naturales presentes en el área, y qué actividades económicas se han organizado y desarrollado a partir de los mismos. Esto permite identificar distintas miradas sobre la naturaleza: desde aquellas que la ven como una fuente de riqueza, con fines económicos y con una idea utilitarista de la misma; a otras que la perciben a partir de una vinculación más armónica entre la sociedad y la naturaleza. Algunos la han visto y aun la conciben desde una mirada lucrativa y/o especulativa, mientras otros la consideran como una unidad en la cual vivir, convivir y reproducirse. Asimismo, se identifican diferentes efectos negativos en el sistema natural producto de la forma en que se han usado y manejado dichos recursos.

Como resultado se identifican tres momentos diferentes que refieren a tres actividades económicas que se han desarrollado en la villa y que se encuentran en estrecha relación con la valorización de ciertos recursos naturales producidas en diferentes momentos de la historia reciente de la localidad. Ello evidencia el carácter social e histórico así como subjetivo del concepto de recursos naturales.

\section{Marco teórico}

El desarrollo de cada una de las actividades económicas realizadas en el área ha dejado sus huellas en el territorio. Inicialmente fue la ganadería, luego la actividad maderera y actualmente el turismo es la actividad por excelencia en la villa. El cambio en el peso relativo de dichas actividades ha ido acompañado de modificaciones en la organización del territorio. Para el desarrollo de dichas actividades económicas ha sido fundamental la presencia de ciertos actores 
sociales y el vínculo o relación que éstos establecieron y establecen con la naturaleza. Ello conduce a pensar en términos de recursos naturales como los elementos o funciones de la naturaleza que el hombre valoriza en un momento dado. (Blanco, Caso, Gurevich y Tobio, 2001). Esto es claramente visible en el presente análisis no solo por la valorización de distintos recursos sino también porque dicha valorización fue cambiante en el tiempo y permitió el desarrollo de distintas actividades económicas. De manera que los recursos naturales no son solo una valorización social e histórica, sino que también es subjetiva, es decir que no necesariamente para todos los seres humanos significa lo mismo, por ende pueden existir discrepancias en cuanto a su uso o manejo y ocasionarse conflictos en torno a ellos así como problemas ambientales.

Hablar de recursos naturales nos conduce a pensar y revisar las ideas y conceptos que se tienen y se han tenido sobre la naturaleza y tal como expresa Gudynas (1999) las concepciones contemporáneas de la misma han sido varias. Se ha pasado de una naturaleza incontrolable y que imponía límites y ritmos al hombre, a una naturaleza que debe ser intervenida para convertirse en una versión civilizada y manipulada. En la medida que ha ido avanzando el control humano sobre la naturaleza se ha ido imponiendo una mirada utilitarista de la misma y han surgido ideas como la de "canasta de recursos" en alusión a la supuesta abundancia e inmensidad de elementos presentes y útiles en la misma. Esto último haciendo alusión a una naturaleza infinita e inagotable.

En los años 1980 surgieron concepciones de la naturaleza desde la economía tratando de economizarla y percibirla como capital natural. Esta postura suponía el ingreso de la naturaleza al mercado y por ende, la mercantilización de la misma. (Gudynas, 1999; Gudynas 2003a). Se acentúa una mirada economicista y utilitarista y por ende, una mirada fragmentada de la misma en la que solo importan los elementos de ésta que resultan útiles para la sociedad. Un dato no menor que destaca el mencionado autor es que también aparece la apropiación privada de dichos elementos. Esta tendencia se observa actualmente en varios lugares, y en el área de estudio se puede asociar con claridad a la actividad turística y la apropiación de sectores de costas de lago, por ejemplo.

Por otra parte, esta idea de incluir la naturaleza en el mercado nos lleva a reflexionar sobre las concepciones de valor de la naturaleza que se hallan implícitas en las principales teorías económicas. En coincidencia con Fernández Esquiza (2003) no se debería reducir la naturaleza a un valor económico. Es necesario recapacitar sobre cuál es el valor o los valores que ésta tiene y como podría medirse (si es que ello es posible). Las nociones de valor de las principales teorías económicas ${ }^{2}$ muestran que todas tienen en común la consideración de la utilidad como condición necesaria y por ello, no pueden dar cuenta de la parte de la naturaleza que no consideran "útil". Hay que asumir que el valor económico de la naturaleza es sólo una de las dimensiones de valoración de la misma pero su valor en sentido amplio es mucho más que el valor de uso y el valor de cambio. (Fernández Esquiza, 2003). En tal sentido, la citada autora propone incorporar el "valor ecocéntrico" haciendo referencia al conjunto de valoraciones, que más allá de ser subjetivas por ser creadas por los seres humanos, reconocen el valor que posee la naturaleza en sí misma y no sólo el asignado por el hombre.

Gudynas (2003a) aborda el tema distinguiendo las diferencias entre los conceptos de capital natural y patrimonio natural. Mientras el concepto de capital natural involucra o facilita el ingreso de la naturaleza al mercado, el de patrimonio natural abre posibilidades para la regulación social sobre el mercado, en tanto es vista como un legado de generación en generación. (Fernández Esquiza, 2003).

\footnotetext{
2 "Desde el punto de vista económico pueden reconocerse claramente dos teorías, una del valor objetivo expresada básicamente por los autores clásicos (Smith, Ricardo, Mill y Marx entre otros) y una teoría del valor subjetivo expresada por los autores neoclásicos (Jevons, Mengers, Paretto entre otros)". (Fernández Esquiza, 2003, p.4)
} 


\section{AMAZONANAS}

Por lo tanto y en coincidencia con Gudynas (2003b), se sostiene la idea de inconmensurabiliad de la naturaleza. Este autor expresa que la naturaleza es inmensurable. Las diferentes medidas tan solo permiten evaluar aspectos parciales y específicos, y sólo a veces son comparables. Es necesario pensar a la naturaleza de otra forma, como sujeto de valor, con una concepción ecocéntrica, y que se reconozca la pluralidad de valoraciones de la misma. Ello permitiría dejar en evidencia aspectos de la realidad oscurecidos por un discurso que ilumina y naturaliza una forma de conocer reducida, fragmentaria y parcial. (Fernández Esquiza, 2003).

La naturaleza es transformada por ciertos actores sociales a partir de la apropiación de un espacio que se constituye como territorio a partir de la intervención de un determinado grupo social que podrá entrar en disputa o no por éste con otro grupo social. De manera que dicho territorio es el resultado no solo de las acciones sociales actuales sino también de los rasgos existentes del pasado en combinación con las características físico naturales que éste presenta (modificadas o no).

Contar con distintas "fotos" de un territorio en diferentes momentos permite aproximarse a la comprensión de su evolución y situación actual. En tal sentido, el presente artículo permite identificar distintos momentos a lo largo de la historia de la localidad en los que se han desarrollado las actividades económicas a partir de la valorización social de diferentes recursos naturales, que han permitido y provocado diversos cambios en dicho territorio como en su organización. La revisión y análisis propuesto a partir de la valoración social e histórica de los recursos naturales permite reconocer distintos momentos en el devenir de la actual villa turística con claras diferencias en la relación sociedad- naturaleza.

\section{Metodología}

El análisis incluye elementos y procesos desde finales del siglo XIX con la inserción de Argentina al mercado mundial hasta sucesos próximos a la actualidad. Este análisis histórico permite distinguir tres momentos con distintas valoraciones sociales respecto a los recursos naturales y, por ende, tres actividades económicas desarrolladas: la ganadería, la actividad maderera y el turismo. Todas han contribuido a la organización del territorio, han dejado sus huellas en el mismo y también, han generado efectos negativos en el ambiente.

Para alcanzar dicho propósito se ha trabajado con fuentes primarias y secundarias. La recolección de las primeras se realizó mediante entrevistas a informantes clave que se realizaron tanto en Pehuenia como en Moquehue. Las mismas fueron semi-estructuradas con una guía de temas a tratar, pero considerando la natural evolución de la charla. Estas formaron parte del intenso trabajo de campo que se realizó en el destino turístico entre los años 2016-2018 donde se realizaron varias visitas al destino.

Los entrevistados han sido antiguos pobladores de la villa, docentes e investigadores que viven allí, personal del municipio en Pehuenia y en Moquehue. Específicamente, las personas entrevistadas fueron antiguos pobladores y pioneros en el desarrollo de la villa turística; miembros de la comunidad Puel y de la Placido Puel; prestadores turísticos de Pulmarí y una docente de la escuela $\mathrm{N}^{\circ} 90 .^{3}$

También se incorporaron documentos legales y se utilizaron fuentes bibliográficas, especialmente del ámbito local que han realizado importantes estudios en el área.

\footnotetext{
${ }^{3}$ En la presente investigación se respeta el principio de confidencialidad y por tal motivo se hará referencia a los entrevistados solo con su primer nombre y su rol o función cumplida por la cual es pertinente la información brindada por éste.
} 
Cabe mencionar que la información que se presentará aquí forma parte de los resultados obtenidos en el marco de la elaboración de la tesis doctoral realizada por la autora.

\section{Resultados}

A continuación, se detallan los tres momentos que refieren a la valoración histórica de los recursos naturales y al desarrollo de ciertas actividades económicas. Junto con ello, se podrá detectar la dinámica relación sociedad-naturaleza.

\section{- Valoración de los recursos suelo, agua y pasturas para la Actividad Ganadera:}

Previo a la ocupación militar por parte del Estado Nacional mediante la Campaña del Desierto ${ }^{4}$, había en la zona población indígena que vivía allí y que dio origen a una ocupación del espacio y a una organización social que se basaba en el desarrollo de una actividad agrícolaganadera ubicada en la zona cordillerana de Neuquén. La agricultura con fines de consumo interno y la ganadería, como intercambio comercial con Chile fue configurando una zona de intercambio y comunicación a ambos lados de la cordillera. (Ciminari, Iglesias, Jurio, Torrens, y Vecchia, 2006). El propio Vicente Puel (ex lonco de la comunidad mapuche Puel), recuerda que sembraban papa, centeno, habas, arvejas, y cuando no helada, podían cosechar. También tenían vacas, caballos y unas pocas chivas y ovejas.

Según la mirada de los centros de poder del país, Neuquén pareció ser más importante en relación al tema de seguridad por ser zona lindante con otro país, que al de incorporación productiva de sus tierras. Ello estaría vinculado con la inexistencia de un mercado mundial donde colocar la producción de ganadería extensiva de la misma, quedando reducida a un mercado local o regional relacionado esto a su aislamiento y mediterraneidad que su paisaje le imprime. De esta manera, quienes arribaron a la provincia neuquina fueron sectores secundarios de los grupos de terratenientes de Buenos Aires o bien, algunos que decidieron probar fortuna con inversiones especulativas. Se observó una concentración en pocas manos de importantes extensiones de tierra que detrás de una supuesta política de poblamiento y de protección de fronteras, condujo a acciones especulativas en la zona.

Para fines del siglo XIX y principios del siglo XX si bien la participación de la ganadería neuquina a nivel nacional era irrelevante, su importancia para el mercado chileno era importante. Para mediados del siglo XIX Chile se hallaba abocado a la producción agrícola de exportación, principalmente por el puerto de Valparaíso. Esa monoproducción dio origen a la demanda de ganado neuquino ya sea para el consumo y/o para la exportación de carnes y derivados.

Las propiedades del territorio de Neuquén que se ocuparon para la actividad ganadera se ubicaron en la zona cordillerana, sector centro y noroeste, (donde se localiza el área de estudio), lo cual dio origen a una mayor y temprana organización social relacionada con la mejor conectividad con Chile. Esta, estuvo facilitada por la poca presencia de bosques y pasos menos accidentados. Ello mismo explica la mayor cantidad de población allí, detallada en los primeros censos nacionales realizados. En esto las condiciones naturales fueron importantes: la notoria disminución de las precipitaciones de oeste a este debido a la circulación atmosférica del aire y a la presencia de la barrera orográfica que constituye la Cordillera de los Andes para el ingreso de masas de aire húmedo desde el océano Pacífico al territorio neuquino, produce un cambio evidente en la vegetación que crece y se desarrolla. Así, al estar al este de la cordillera y con menores precipitaciones, los bosques son menos densos en Argentina que del lado chileno; las pasturas naturales son adecuadas para el ganado, y la presencia de valles transversales posibilitaban el paso

\footnotetext{
${ }^{4}$ Fue la campaña militar realizada entre los años 1878 y 1885 por la que se conquistó grandes extensiones de territorio, en este caso en Patagonia, que estaban en poder de los pueblos originarios.
} 


\section{AMAZONANAS}

por la cordillera. A lo que se le añade la presencia de una importante infraestructura de caminos heredadas de las comunidades indígenas que desde el norte neuquino se conectaban con Chile.

Así, mientras las principales regiones argentinas producían para exportar por el Atlántico a Europa, Neuquén lo hacía para Chile, con predominio de bovino en función de la demanda.

Lo relatado precedentemente da cuenta de una valoración social por parte de aquellos antiguos pobladores respecto de los recursos naturales presentes (suelo, pastizales y agua) en la que se destacan sus características originarias para abrir caminos y transitar con ganado así como para criarlos, alimentarlos y permitir su intercambio con el país vecino.

Bandieri (1993) destaca dos etapas en el desarrollo de la actividad ganadera de la provincia de Neuquén. Una primera etapa (1879-1900) donde el centro de la actividad ganadera se localizó en el Noroeste-Centro Oeste neuquino en tanto que en la segunda etapa (1900-1930) se extendió hacia el sur provincial.

La primera etapa (1879-1900) constituye el periodo de mayor auge del ciclo ganadero regional. En esos años, y en línea con lo expresado en párrafos previos, se constituyó el desarrollo de economías complementarias y a su vez de dependencia con actividades de transformación del lado chileno. Mientras que en Neuquén se producía la cría y engorde de animales y era quien proveía carnes y derivados, lana y pelo caprino; en Chile se producía la comercialización de ello y a su vez, era quien proveía productos de consumo básicos como vino, arroz, parafina, té, harina, jabón, maderas, aguardientes, fideos, entre otros. "En este contexto, Moquehue era uno de los lugares utilizados como zona de paso y comunicación entre ambos países." (Ciminari, et al. 2006, p.7).

A inicios del siglo XX y en coincidencia con la segunda etapa (1900-1930) identificada por Bandieri (1993), se incorporan a la actividad el resto de la zona cordillerana y antecordillerana mediante grandes establecimientos ganaderos en el sur, privatizados luego de la conquista militar. Ya en los años 1930 comienza a declinar este fluido comercio fronterizo vinculado a la crisis internacional; a las medidas proteccionistas de Chile que pretendían motivar su propia producción, y a los controles aduaneros de Argentina de los años '40 interrumpiendo definitivamente el mercado. De esta manera, se modificaron los flujos de circulación, con serias consecuencias sociales, y afectando de forma disímil a los distintos actores sociales involucrados. En ese momento, la única alternativa para los productores era el mercado nacional pero la desvalorización de los precios de hacienda y la falta de un sistema integrado de comunicaciones con el área del Atlántico dificultaba aún más la situación ya que la única alternativa era pagar altos fletes hasta Zapala que era punta de rieles. Ello condujo también al despoblamiento de áreas cordilleranas ya visibles en el censo nacional de 1947. Por su parte, las empresas más importantes comenzaron con cierto mejoramiento de razas e incorporación tecnológica, con el propósito de poder colocar su producción en el mercado nacional.

El desarrollo de la actividad ganadera supuso la valorización social de los recursos naturales suelo, vegetación y agua. El uso y manejo de los mismos se caracterizó por un mal manejo de éstos, lo cual provocó sobrepastoreo, degradación de suelo y de vegetación, procesos de erosión e ineficaz aprovechamiento del recurso agua entre otros. (Bandieri, 1993) ${ }^{5}$. La gran carga animal con destino a Chile habría generado un fuerte impacto en la degradación de suelos en los sectores utilizados como rutas de arreos. Situación que se ha empeorado aún más, en décadas posteriores con la práctica de ganadería caprina.

\footnotetext{
${ }^{5}$ Hoy se puede decir, basándose en diversos estudios realizados por profesionales de distintas disciplinas que el uso y manejo de los recursos no ha sido el adecuado. Sin embargo, hay que contemplar el posible desconocimiento que se tenía en esos años sobre los procesos naturales y las posibles consecuencias del accionar humano.
} 
De esta manera, la actividad ganadera fue la predominante y fue la que orientó el proceso de organización espacial y apropiación inicial de la tierra así como la circulación regional, durante las últimas décadas del siglo XIX y las primeras del siglo XX. Igualmente fue determinante para el crecimiento poblacional de los primeros asentamientos localizados en el centro oeste y noroeste de la provincia.

Asimismo, cabe destacar que uno de los recursos naturales valorados en esos años pone en evidencia el carácter subjetivo de los mismos, ante la diferente valoración que se evidenció por parte de los distintos actores sociales, durante este periodo analizado. Puntualmente se hace referencia al suelo y a la distinta valorización entre la población que vivía en la zona y tenía vínculos comerciales con Chile, y aquella que desde Buenos Aires pretendía tener control y poder sobre esta región andina. Con motivo de la Campaña del Desierto existió una valoración del recurso suelo pero no siendo visto éste como un factor de producción ni como un territorio donde se pretendiera extender la producción ganadera. La valoración de este recurso natural tuvo otra connotación en la provincia del Neuquén para el estado nacional y se vinculó con la intención de garantizar la seguridad y defender la frontera con Chile y en segundo término, con la apropiación privada y especulativa de la tierra.

Muy distinta a ésta fue la valoración del recurso suelo que realizó la población indígena así como los comerciantes chilenos, que vieron en estas tierras la posibilidad de subsistir y de comercializar su producción ganadera en el caso de los primeros; y de intercambiar y realizar una producción complementaria con la agricultura que se efectuaba por esos años del otro lado de la cordillera para los segundos. Para ambos, la producción ganadera significó una valoración productiva del suelo, pero también de las pasturas y del agua como sustento alimenticio del ganado. Incluso para la población local no solo tuvo una valoración económica sino también una valoración social, porque era allí donde vivían, donde criaban sus animales y cuidaban de sus hijos. Esas tierras eran su "lugar".

Esto permite identificar esas distintas miradas que existieron sobre la naturaleza, algunas más utilitaristas y con fines económicos que otras. Lo cierto es que a partir de la concepción que se ha tenido de la misma, es posible comprender las acciones que se realizaron a posteriori y la racionalidad que las acompañó.

\section{- Valoración del Recurso Maderero para la Actividad Forestal.}

Si bien esta actividad no tuvo la relevancia que obtuvo la ganadería, contó con un momento de auge considerable en la zona andina que merece ser considerado.

Bandieri (1993) identifica dos etapas en la provincia de Neuquén: de 1895 a 1950, y de 1950 a 1970, sin antecedentes previos a la ocupación militar entre los años 1879 y1885.

En la primera etapa (1895-1950), se produjo una extracción sin control de árboles, desmontes con liberalidad en las costas de ríos y arroyos más allá de lo estipulado en el Código Rural de Territorios Nacionales, (LEY N ${ }^{\circ} 3088,1894$ ). Fue una etapa de explotación cuasi-libre de los bosques fiscales más allá de las tres oficinas aduaneras creadas a partir de 1925 y de las normas que prohibían ese accionar. (Bandieri, 1993). Ello estuvo vinculado con la instalación de fuerzas militares y las primeras poblaciones y/o diversas actividades productivas como la ganadería extensiva que requería la apertura de campos para el pastoreo y que temporalmente coincidió con su etapa de auge ya mencionada.

En la década de 1930 comienza la gestión de Parques Nacionales (creada en 1934) que pretendió tener fines conservacionistas, pero en sus acciones se orientó a priorizar la construcción de obras viales y de infraestructura para el desarrollo del turismo internacional así como a 


\section{AMAZONANAS}

consolidar la frontera a partir de una mayor ocupación del espacio mediante la creación de varios pueblos y villas. (Bandieri, 1993). En los años de 1940, durante el mandato del presidente Perón, se orientaron las acciones a favorecer el turismo nacional y se observó una actitud más proteccionista. Esta primera etapa se caracterizó por pocos aserraderos, una mínima transformación in situ, y se mantuvo hasta finales de dicha década cuando se tomaron medidas protectoras de los bosques y se habría frenado el manejo irracional y cuasi libre, con menos concesiones y más exigencias. Por esos años las principales áreas de explotación se encontraban en el sur provincial, sin indicios de explotación en el departamento Aluminé (donde se halla el área de estudio), hasta 1949. (Bandieri, 1993).

La segunda etapa de la actividad en la provincia se identifica entre los años 1950-1970. Durante estas décadas se produjo el mayor desarrollo de la actividad coincidiendo con el otorgamiento de muchos permisos de extracción (en especial en San Martin de los Andes y Moquehue); con una actitud más permisiva de la Administración de Parques Nacionales y, con el derrocamiento de Perón. Todo habría favorecido a un desarrollo cuantitativo de la actividad, así como a un deterioro muy grande del recurso natural. Fueron varios años de mal manejo técnico y descontroles administrativos que favorecieron una explotación irracional, con talas indebidas. De hecho, durante esta segunda etapa la Administración Nacional de Bosques otorgó dos concesiones por superficie para explotar forestalmente durante varios años. Una de ellas, fue para la empresa Zubillaga en la zona de Quillén ${ }^{6}$ entre los años 1947 y 1965, y la otra, para la empresa Compañía Industria Forestal, del señor Colombo en la zona de Moquehue desde el año 1949 hasta 1966. Si bien ambas se encontraban ubicadas en el departamento Aluminé, a los fines de este escrito se hará foco en la explotación de Colombo, por su localización en el área de estudio.

En dialogo con Orlando A., (antiguo poblador de la villa, entrevistado en mayo 2017), quien trabajó junto a Colombo, comenta que tenían 3 turnos y se trabajaba las 24 horas. Contaba con unas 800-900 personas trabajando entre Zapala y el monte, en tanto que según Martin C., (actual prestador turístico en Moquehue, entrevistado en diciembre 2016) habla de unos 10001200 empleados. Más allá de las diferencias, el número da una idea de la envergadura del proyecto que duró varios años. ${ }^{7}$ De hecho el movimiento en Moquehue era tan importante que el paraje tuvo una pista de aterrizaje, en la actualidad fuera de uso.

La concesión nacional le dio a Colombo la posibilidad de explotar $7.000 \mathrm{~m} 3$ de madera por año pero según datos de los viejos pobladores, se explotaron cerca de $20.000 \mathrm{~m} 3$ en especial en los primeros años donde la fiscalización era menor. (Bandieri, 1993).

La magnitud de la explotación lleva a reflexionar sobre las miradas que prevalecieron en aquel momento sobre la naturaleza. ¿Se pensaría en una naturaleza inagotable, sin límites? ¿Sería una mirada que se enfocaba en la visión utilitarista y en obtener réditos económicos? ¿Habría desconocimiento de las consecuencias de sus acciones o la mirada fragmentada también estaba presente y solo importaba extraer las especies "útiles"? Creo que ha habido una mezcla de todas estas posibilidades con acciones que están atravesadas por una racionalidad económica que buscaba maximizar ganancias en corto tiempo, quizá por ello la cantidad de empleados y el trabajo sin descanso durante todo el día.

La actividad de Colombo en Moquehue terminó a fines de los años de 1960 según Orlando A. por cuestiones políticas. Hubo otras empresas con aserraderos pero todas de menor envergadura y de corta duración. Esta segunda etapa identificada por Bandieri (1993) coincidió con la época de mayor crecimiento del paraje Moquehue vinculado a la gran cantidad de

\footnotetext{
${ }^{6}$ Ubicado en el sur del departamento Aluminé

${ }^{7}$ Según el Censo Nacional de Población y Vivienda, la población de la villa era solo de 1.611 personas en 2010 , y producto del desarrollo de la actividad maderera, supo tener más de un millar de trabajadores 50 años atrás.
} 
empleados de Colombo que se radicaron junto a sus familias. El desarrollo y crecimiento de esta actividad económica determinó cambios en la organización del territorio de la actual villa turística. De hecho, surgió la "Bella Durmiente" en Moquehue, primeramente como un lugar de ramos generales y luego como la primer hostería de la zona, con el propósito de brindar servicios a esta población creciente. Asimismo, comenzaron a surgir ciertos comercios y lugares de alojamiento en la zona de La Angostura ubicada en la unión de los Lagos Aluminé y Moquehue, zona en la que se descargaba la madera transportada en balsas desde Moquehue. Uno de ellos fue el primer almacén de ramos generales que correspondía a Orlando A. y su esposa Ester G., y que abastecía a toda esa población, según expresa Teresa P. (docente jubilada de la zona). A ello, se sumó la presencia de algunas instituciones en la zona que impulsaron aún más la presencia de población en dicha área. Allí, se encontraba la primera escuela pública, la No. 90 desde 1926; una repartición de Gendarmería Nacional a partir de 1943 (Guía Pehuenia, s/f); el vivero provincial y el primer destacamento de Vialidad. De esta manera la zona de La Angostura se constituyó en el "centro" o zona comercial de Pehuenia que tiempo después se trasladaría a lo que actualmente se denomina "centro comercial". Es decir, por un tiempo la actividad maderera organizó el territorio y fue determinante en el surgimiento de esta área que por esos años se convirtió en la zona céntrica y comercial de lo que hoy se conoce como la villa turística.

Puede decirse que Moquehue, punto neurálgico de esta actividad económica, tuvo su origen y crecimiento muy ligado al desarrollo de la misma y estimuló el asentamiento permanente de población. Sin desconocer que previo a la década de 1940, la actividad ganadera y el comercio con Chile fueron las actividades que dieron lugar al surgimiento de los primeros asentamientos de población dispersa en la región. (Torrens y Steimbreger, 2010).

Como ya se expresó, para mediados de 1960 la actividad fue mermando, las dos grandes empresas mencionadas previamente (Zubillaga y Colombo) finalizaron sus explotaciones, y desde los años 1970 una nueva y diferente etapa para la actividad forestal se inició. Se suspendió el otorgamiento de nuevas concesiones de explotación pero también se observaron algunos acuerdos y excepciones con ciertos agentes madereros. (Bandieri, 1993). A nivel provincial, en Neuquén se creó CORFONE (1974), una corporación forestal formada por capitales del estado y privados, destinada a la forestación y explotación de bosque nativo. La misma posee campos en Campo Lolog y en Lago Quillén, así como aserraderos. Ésta ha llevado a cabo tareas de reforestación pero "...no se ha logrado frenar el deterioro del bosque nativo, especialmente en el caso de la araucaria por el tiempo que demanda su crecimiento..." (Bandieri, 1993, p. 233), vinculado a cuestiones naturales pero principalmente a un uso irracional en el pasado. Además, las especies elegidas para reforestar no han sido las más convenientes como tampoco sus efectos en relación a las nativas ${ }^{8}$.

Por lo detallado precedentemente, puede decirse que si bien la actividad forestal tuvo su momento de auge durante los años de 1950-1970, ésta se desarrolló como un enclave extractivo y no actuó como una actividad dinamizadora de la economía provincial. De hecho, cuando las empresas más importantes se retiraron y abandonaron la actividad, mucha de la población que se había instalado allí decidió migrar a otras áreas quedando solo un reducido número de habitantes permanentes. (Ciminari, et al, 2006). Sin embargo, su incidencia fue destacable en el caso de Moquehue. Allí se produjo la instalación de una planta industrializadora de maderas compensadas en su momento de auge, y durante esos años produjo un interesante movimiento y dinamismo en el área de estudio, pero luego ello finalizó y la zona que supo ser el centro de mayor circulación social y comercial dejó de serlo con la caída de la actividad.

\footnotetext{
${ }^{8}$ Según explica Gerardo de J. (investigador y habitante de la villa, entrevistado en mayo 2017) se han plantado especies de pinos que no tienen tan buena madera (murayana y ponderosa). Además, producen acidificación del suelo, provocando la muerte de casi todo lo que puede crecer debajo de estos. Su crecimiento y reproducción es más rápido que el de las nativas.
} 


\section{AMAZONANAS}

En lo que refiere al uso y manejo de los recursos naturales significó un periodo de gran deterioro del bosque nativo con la tala de muchos ejemplares de forma irracional y principalmente con la pérdida de araucarias cuyas consecuencias aún no se han superado debido al lento crecimiento de dicho árbol. Fue un periodo con una clara racionalidad capitalista que en ningún momento consideró un manejo sostenible del recurso respetando los tiempos de recuperación y crecimiento de las especies arbóreas.

\section{- Valorización de los Recursos Naturales con Fines Turísticos}

En el área de Villa Pehuenia-Moquehue se repitió, como en otros destinos tales como en Bariloche y San Martin de los Andes, una secuencia de actividades económicas vinculadas a lo agrícola-ganadero y lo forestal para luego, comenzar el desarrollo del turismo como actividad principal. Una pionera en el desarrollo turístico en la zona de estudio fue la señora Evangelina C. quien en el año 1967 desarmó su aserradero (ubicado en Moquehue) y empezó a construir una casa de tres plantas que se convertiría luego en una hostería. ${ }^{9}$ Este puede considerarse como el puntapié inicial del paraje con un incipiente perfil turístico unido a lo agrícola-ganadero, ya que contaba con animales, hortalizas y un almacén para el autoabastecimiento. Asimismo, en la zona de Villa Pehuenia a finales de los años 1960 y principios de los 1970 surgen pequeñas aglomeraciones de población separados por pocos kilómetros entre sí. Estas son: Villa Unión, Villa Italia, La Angostura y Lonco Luan. Algunos surgieron producto de una incipiente demanda turística y otros eran asentamientos preexistentes de comunidades mapuches. (Torrens y Steimbreger, 2010).

En los años 1970 y 1980 comienza el accionar del estado provincial para poner en valor los recursos naturales existentes en pos del desarrollo turístico, a la par que la actividad maderera declinaba. Cabe destacar el rol activo de los primeros pobladores que, ante la merma de la actividad forestal, impulsaron la creación de la comisión de fomento porque vislumbraron que el turismo podía ser la alternativa para generar empleo.

\section{Valoración y cesión de las tierras para la futura villa turística}

Para el desarrollo turístico de la zona era fundamental contar con tierras disponibles para tal fin y las mismas habían sido otorgadas, mediante convenios con el Estado Nacional, a las comunidades mapuches Puel - en la zona de las costas norte de los lagos Aluminé y Moquehue y en la zona de La Angostura entre ambos. (Guía Pehuenia, s/f). La mayoría de los entrevistados apuntan al por entonces lonco de la comunidad Puel, Vicente Puel como el responsable de ceder las tierras sin el consentimiento de ésta. Por su parte, Vicente manifestó que quien acordó con el gobernador Sapag, fue su padre Olegario, quien no sabía leer, solo firmar. ${ }^{10}$ Este acuerdo fue determinante y constituyó un punto de inflexión en los años venideros en varios aspectos. A partir de allí hubo un quiebre entre la práctica ganadera y de cultivos por un lado, y el turismo por el otro, ya que desde ese momento prosperaron los estudios necesarios y la mensura catastral del ejido. En 1989, se creó la Comisión de Fomento y allí el turismo tomo impulso. Además, implicó un creciente y sostenido arribo de nuevos pobladores a la villa que no ha mermado. Y por último, significó un quiebre al interior de la comunidad Puel ya que algunos miembros, enojados con Vicente por la cesión de tierras y pérdida de áreas de pastoreo, decidieron separarse de la agrupación y crearon la comunidad Placido Puel que aun hoy existe.

En una entrevista realizada en mayo 2017 a Noemí B. (arquitecta y empleada de la Dirección Provincial de Tierras en los años 1970-80), que participó en la planificación de Villa

\footnotetext{
${ }^{9}$ Inicialmente sirvió de alojamiento a los técnicos y agrimensores que trabajaron en la apertura del camino que une Moquehue y Pehuenia. Desde 1968 se convirtió en la Casa de familia y hostería Bella Durmiente. Antonieta C., una de las propietarias herederas de la hostería, fue entrevistada en diciembre 2017.

${ }^{10}$ Para mayor detalle se sugiere la lectura de Di Nicolo (2020).
} 
Pehuenia-Moquehue brindó algunos datos interesantes. La planificación inicial incluyo a Villa Unión y Villa Italia, no así el actual barrio Parque Industrial cuya formación es más reciente. Si bien se tomaron medidas para evitar la especulación, se han detectado falencias en distintas áreas como Pulmarí, zona de La Angostura, Moquehue, Altos de Pehuenia. Una de esas zonas ha sido Moquehue con complejos problemas en cuanto a la apropiación de tierras. De hecho, a partir de los años 1985-90 el paraje se definió como "un reparto de tierras entre amigos", en palabras de Martin, C. (entrevistado en diciembre 2017). Se dividieron todos los terrenos de la costa sudoeste y norte del lago Moquehue, ocupados por privados y quedando reducidos los accesos públicos al lago. ${ }^{11}$

De esta manera, los estudios realizados en la zona, las normativas sancionadas y la posterior venta y/o entrega de terrenos, dieron inicio a una puesta en valor de los recursos naturales presentes en torno a los lagos Aluminé y Moquehue.

\section{-Etapas de crecimiento de la villa turística y densificación poblacional.}

El 20 de enero de 1989 se crea la Comisión de Fomento de Villa Pehuenia, y en el año 2003, se crea el municipio de Villa Pehuenia-Moquehue con rango de tercera categoría. (LEY PROVINCIAL $N^{\circ} 2439,2003$ ). Dos años más tarde comienza una densificación de la villa a partir de la subdivisión de lotes en parcelas de menor tamaño y un incremento en las edificaciones. Este proceso va de la mano de un claro crecimiento poblacional que evidencia la villa en los últimos años. Según datos de los Censos Nacionales de Población y Viviendas del INDEC (Instituto Nacional de Estadísticas y Censos), la localidad pasó de 155 habitantes en 1991; a 743 en 2001; y a 1.600 en 2010. A ello cabe aclarar que hay muchas personas que cuentan con viviendas de segunda residencia y que seguramente no fueron registradas en dichos procedimientos de recolección de datos mencionados. Dichos números pueden llegar a duplicarse durante los meses de verano con la llegada masiva de turistas, con todo lo que ello implica y puede provocar a la villa. De hecho el intendente Badilla expresó en enero de 2016 que en ese momento vivían en la villa “... 2.300 personas, sin contar las 750 casas de segunda residencia o las 3.000 plazas turísticas". (Diario Rio Negro, 2016). Dicho crecimiento poblacional permitió que en septiembre de 2018, el municipio fuera recategorizado como municipio de segunda categoría por parte de la Legislatura provincial neuquina. (Diario La Mañana Neuquén, 2018).

Así, con esta nueva actividad económica como protagonista se produce una valoración social por el uso y consumo in situ de los recursos naturales cuya belleza paisajística atrae tanto a turistas como a empresarios/inversores. Pero a su vez, se da una nueva valoración por el recurso suelo que supone una apropiación privada del mismo con intenciones urbanísticas ya sea para construir viviendas de segunda residencia o bien, alojamientos turísticos. Muy distinta es la actual valoración social a la realizada antaño con fines relacionados a la actividad ganadera o a la forestal.

Con el desarrollo del turismo se evidencia con claridad la mirada economicista y utilitarista que se tiene de la naturaleza. Esa idea de capital natural (Gudynas, 2003b) que supone la mercantilización de la misma y a su vez, un proceso no menor: la apropiación privada de ésta. Aquí la apropiación privada de terrenos con vistas privilegiadas y costas a los lagos, supone el disfrute y acceso de unos pocos, y una importante rentabilidad para quienes son sus propietarios. Ello se observa tanto en sectores del lago Aluminé como del Moquehue.

\footnotetext{
${ }^{11}$ También hubo problemas con las tierras que poseían los pobladores preexistentes (pobladores de ley). Martin, C. relata que las tierras que ocupaban no las podían vender, ni cambiar pero muchos de ellos las subdividieron y vendieron sin la autorización debida. Todo dio como resultado un crecimiento desorganizado del paraje. Para mayor información se sugiere la lectura de Di Nicolo, (2018).
} 


\section{AMAZONANAS}

Asimismo, cabe mencionar algunos problemas ambientales que han surgido en los últimos años y/o se han acrecentado, como la contaminación de los lagos por vertido de líquidos cloacales, modificaciones de laderas y/o tala de árboles para edificar, incendios forestales, así como situaciones irregulares en cuanto al otorgamiento y tenencia de tierras. Situaciones que están directa o indirectamente relacionadas con el turismo, con la valoración de ciertos terrenos, con la búsqueda de rentabilidad y con el crecimiento poblacional que ha tenido la villa. Una planificación ineficiente y/o que ha sido superada por la realidad contribuyen a comprender esta situación.

Así la realización de estudios, sanción de normas, inversión en infraestructura de servicios y en caminos, y demás, se han realizado por la valorización por parte de ciertos actores sociales por los recursos naturales con fines turísticos presentes en el área. Dichos atractivos junto con la promoción turística y el surgimiento de diversos servicios básicos (alojamiento, gastronomía, etc.) en los últimos años, han permitido que el turismo se consolide como "el eje dinamizador de la economía regional." (Ciminari, et al, 2006, p.9).

En lo que refiere a la organización territorial, la localidad se ha volcado hacia las costas de ambos lagos, esas zonas son muy valorizadas actualmente y es allí donde se concentran muchos alojamientos y viviendas particulares. Incluso, en cercanías a "la península" en el lago Alumine, el estado provincial ha realizado varias obras que le han otorgado valor y la han convertido en un atractivo turístico de la villa.

De esta manera las diferentes valoraciones de los recursos naturales han dado origen a distintas actividades económicas. Producto de ello, se han plasmado en el territorio las especificidades propias de cada una. Así, diversos procesos producto de la relación sociedadnaturaleza se han territorializado. En palabras de Galafassi (2019)

... para comprender la ocupación, modificación y construcción de lo territorial se hace necesario primero tener presente las características que asume la articulación naturalezasociedad, por cuanto el territorio y su aprovechamiento y usufructo será el resultado de esta articulación mediada. (Galafassi, p. 27).

\section{Conclusiones}

La valorización de distintos recursos naturales y el desarrollo de diferentes actividades económicas a lo largo de los años dan cuenta de una dinámica relación sociedad-naturaleza.

Todas estas actividades han sido importantes, aunque con sus particularidades, en la organización del territorio. En tal sentido, en un primer momento la valorización del suelo y los pastizales junto al agua con el propósito de desarrollar la ganadería estuvo claramente vinculada a una histórica relación de economías complementarias que se llevó a cabo durante décadas junto a Chile. La misma produjo un claro deterioro del recurso suelo, en especial en las zonas que se convirtieron en las rutas de arreo.

Años más tarde, la valorización del recurso forestal dio impulso al desarrollo de la actividad maderera. La misma generó la instalación de aserraderos y el arribo de cientos de trabajadores y con ellos, el surgimiento de diferentes comercios. El auge de dicha actividad dio origen a asentamientos en la zona de Moquehue, La Angostura y alrededores, de forma permanente. Su desarrollo también significó un gran deterioro del bosque nativo situación que aun hoy no se ha podido remediar. 
Por último, la valorización de los recursos naturales que combinan una belleza paisajística acompañados de tranquilidad y serenidad para el desarrollo de la actividad turística, comenzó en los años 1970. La misma ha generado el creciente arribo de turistas y de población permanente.

Situaciones problemáticas vinculadas al manejo de los recursos naturales también se han visualizado en relación a esta nueva actividad generando modificaciones, deterioro y la apropiación privada de algunos de ellos. Es una actividad económica que, como las anteriores, se sustenta esencialmente en los recursos naturales. Sin embargo, las evidencias demuestran nuevamente un manejo inapropiado e irracional de los recursos naturales en la región, que ha provocado diferentes consecuencias en ellos. Las preguntas que surgen entonces son, si los problemas ambientales se acrecientan ¿cómo podrá sostenerse el desarrollo del turismo siendo la belleza natural y la calidad paisajística de los recursos naturales la materia prima sobre la cual se sustenta? ¿Habrá que pensar en que se valorizarán otros recursos naturales y darán inicio a otra actividad económica, como también ha sucedido a lo largo de los años? ¿Podrá ser una nueva actividad no vinculada directamente con la naturaleza? Es difícil de imaginarse esto último porque siempre la región valoró distintos recursos naturales pero lo que sí está claro es que la calidad paisajística y su fisonomía no es la misma que hace 30 o 50 años. El problema no es el turismo, ni la ganadería o la actividad forestal, la raíz hay que buscarla posiblemente en la forma en que cada una de estas actividades se han llevado a cabo. En el uso y manejo de los recursos naturales, en la intensidad con que se utilizan y apropian, y la voracidad con que se explotan. Ese ritmo responde a necesidades económicas y desoye las necesidades que demanda y requiere la propia naturaleza para adaptarse a dichos cambios sin sufrir trasformaciones irreversibles. Quizá la diversidad cultural, también convertida en atractivo turístico, y con ello las distintas miradas sobre el medio natural que poseen las comunidades mapuches puedan brindar sugerencias en este sentido. Es necesario reflexionar entonces sobre el valor de la naturaleza haciendo foco en que su valor económico es solo una de las tantas dimensiones de valoración de la misma pero no la única. Es aquí donde el valor ecocéntrico propuesto por Fernández Esquiza (2003) toma protagonismo y da cuenta que es necesario asumir la existencia de valoraciones diversas, así como la inconmensurabilidad de la misma.

\section{Referencias bibliográficas}

Bandieri, S. (1993). Actividades Económicas y Modalidades de Asentamiento. En S. Bandieri, O. Favaro, y Morinelli, M. Historia de Neuquén. Editorial Plus Ultra. Bs. As.

Blanco, J., Caso, M., Gurevich, R., \& Tobio, O. (2001). Los recursos naturales desde una perspectiva histórica-social. En J. Blanco, M. Caso, R. Gurevich y O. Tobio, Notas sobre la enseñanza de una Geografía Renovada. Aique. Bs As.

Ciminari, M., Iglesias, A., Jurio, E., Torrens, C. y Vecchia, M. T. (2006). Ocupación del Territorio y Problemática Ambiental en el Paraje Moquehue, Provincia del Neuquén, Argentina. Ponencia presentada en $52^{\circ}$ Congreso Internacional de Americanistas. España. https://ceasig.uncoma.edu.ar/publicaciones/index.html

Di Nicolo, C. (2018). Análisis de la actividad turística y sus efectos ambientales: El caso de Villa Pehuenia-Moquehue, provincia del Neuquén. (Doctora en Geografía) Facultad de Humanidades y Ciencias de la Educación de la Universidad Nacional de La Plata.

Di Nicolo, C. (2020). Conflicto territorial y Desarrollo Turístico en Villa Pehuenia-Moquehue, Provincia de Neuquén. Revista de Historia. N²1. Pp 207-226. Facultad de Humanidades, Universidad Nacional del Comahue.

Fernández Esquiza, A. (2003) El valor de la naturaleza: los límites de las concepciones utilitaristas. Estudios Socioterritoriales. Pp. 57a 79. Facultad de Ciencias Humanas UNCPBA/CONICET. Buenos Aires, Argentina

Galafassi, G. (2019). De la mediación social de la naturaleza a la construcción histórica del territorio. En D. Pérez Roig, G. Barrios García, y E. Acsebrud, E. (comp.) Naturaleza, Territorio y Conflicto en la trama capitalista contemporánea. Extramuros Ed. 


\section{AMAZÓNAS}

Gudynas, E. (1999). Concepciones de la naturaleza y desarrollo en América Latina. Revista Persona y Sociedad. 13 (1), 101-125

Gudynas, E. (2003a) El Impacto de la Mercantilización de la Naturaleza en la Investigación y la Sustentabilidad. En Memorias del Simposio Internacional Prioridades de Investigación Científica sobre Recursos Naturales Renovables para el Desarrollo Sostenible, Carmen Miranda Larrea (editora). Ministerio Desarrollo Sostenible (Bolivia) e Instituto Conservación Biodiversidad, Academia de Ciencias de Bolivia, La Paz.

Gudynas, E. (2003b). Ecología, Economía y Ética del Desarrollo Sostenible. $4^{\circ}$ edición. ILDISFES. Quito, Ecuador: Ediciones Abya-Yala.

Torrens, C., y Steimbreger, N. (2010). Diversificación Productiva y Ocupacional. Una mirada a la dinámica de los pueblos rurales en el ejido de Villa Pehuenia, prov. del Neuquén, Argentina. Ponencia presentada en VIII Coloquio de Transformaciones Territoriales. Facultad de Ciencias Económicas - UBA. Buenos Aires, Argentina

\section{Otras Fuentes:}

Diario La Mañana Neuquén. (2018). Villa Pehuenia se va para arriba. Recuperado de https://www.lmneuquen.com/villa-pehuenia-se-va-arriba-n604879

Diario Rio Negro. (2016). Mira como creció. Recuperado de http://www.rionegro.com.ar/sociedad/mira-como-crecio-villa-pehuenia-para-disfrutarNARN_8050846.

LEY No. 3088, Código Rural Para Territorios Nacionales. Sistema Argentino de Información Jurídica BUENOS AIRES, 11 de agosto de 1894. Recuperado de http://www.saij.gob.ar/legislacion/ley-nacional-3088-codigo_rural_para_terri torios.htm

LEY No. 2439. Poder Judicial de Neuquén, Argentina. 04 de octubre de 2003. Recuperado de http://200.70.33.130/index.php/normativas-provinciales/leyes-provinciales/1219 3

Sitio Guía Pehuenia. Historia(s/f). Recuperado de http://www.guiapehuenia.com.ar/info/ver/12 